\title{
عرضن [صرة
}

\section{لهداد: ألهملكلزي}

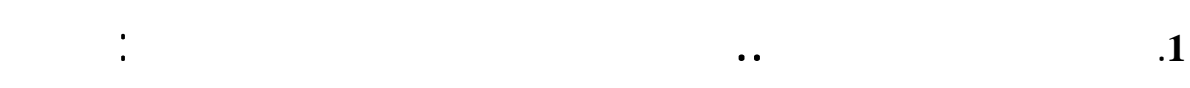

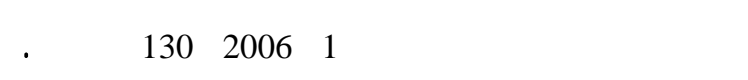

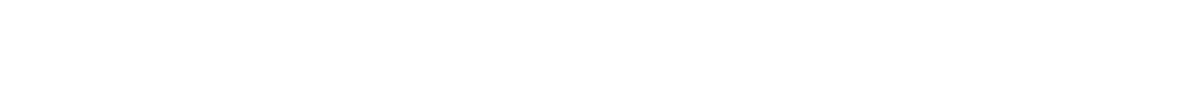

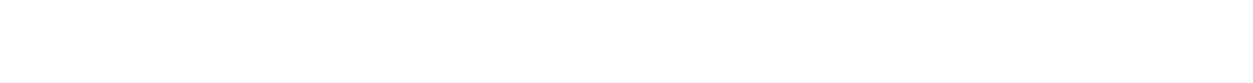

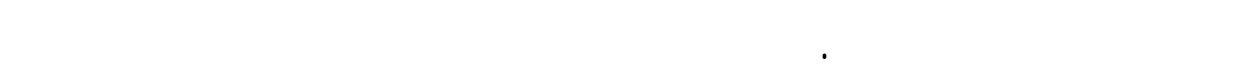

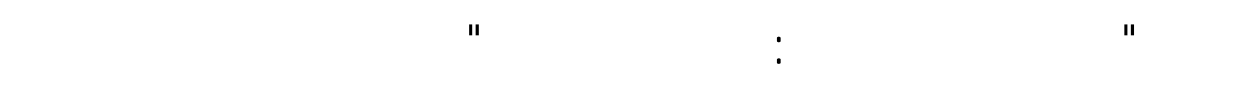

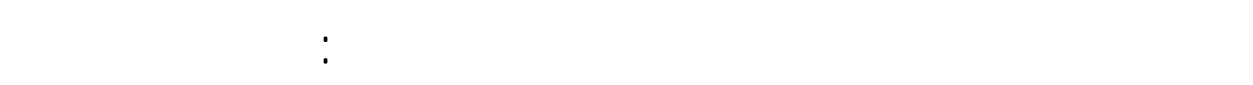

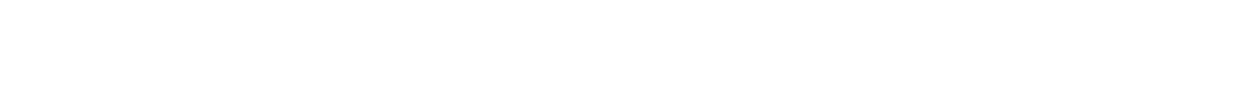

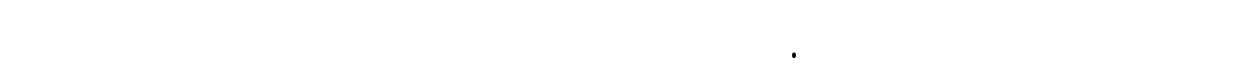

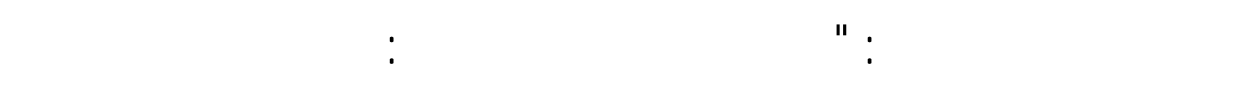

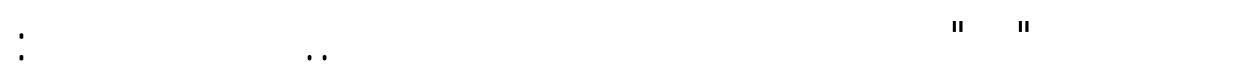

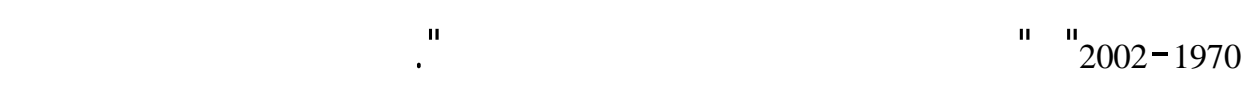

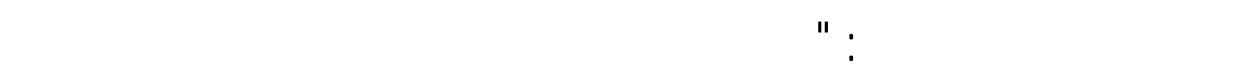

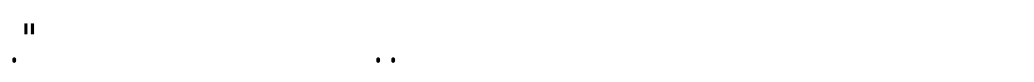

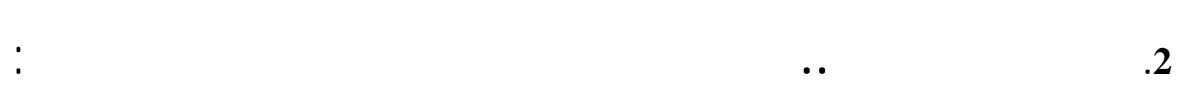

مكتة الشروق الدولة، 2005، 126صفهة.

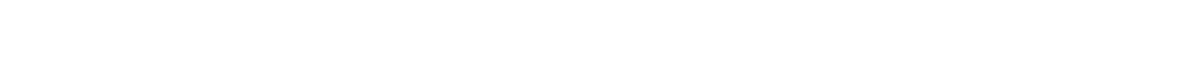

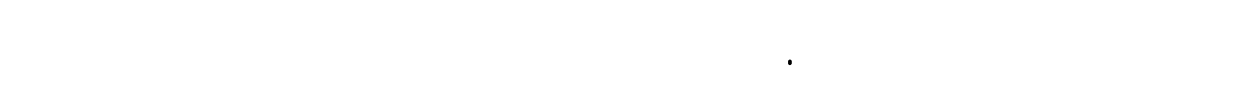




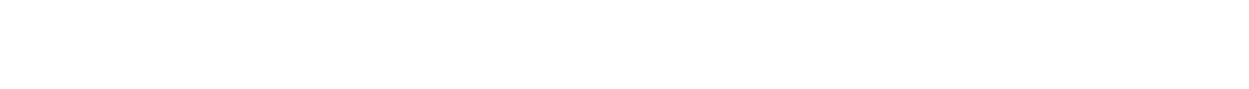

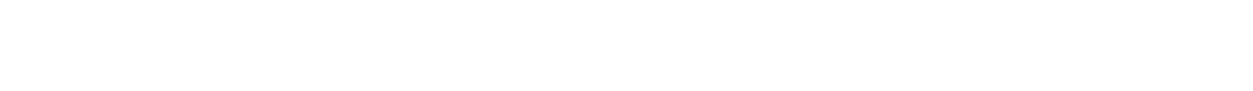

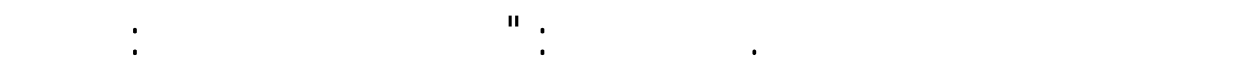

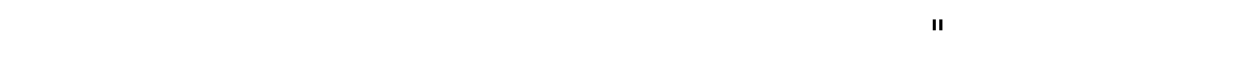

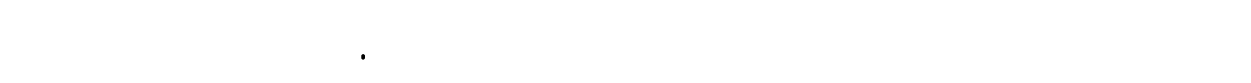

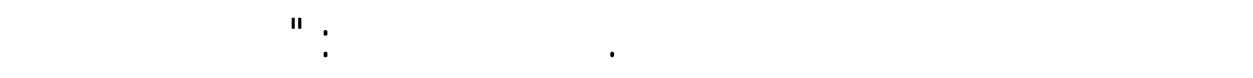

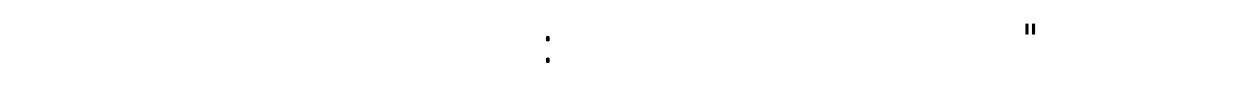

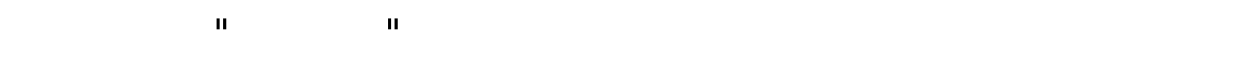

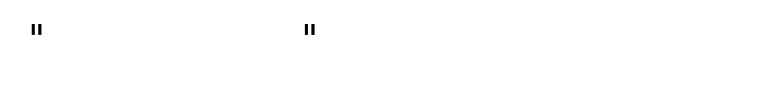

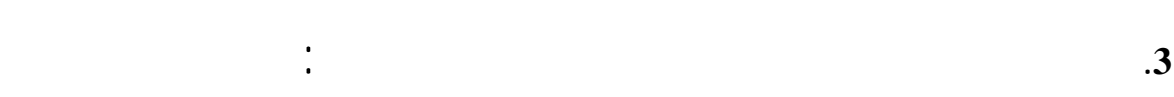

الدولية، 2006، 8ندففة.

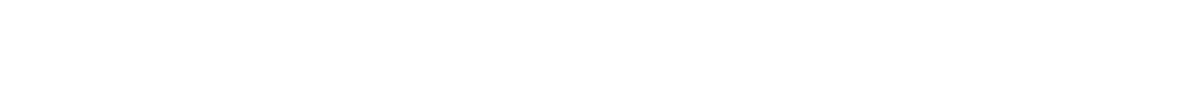

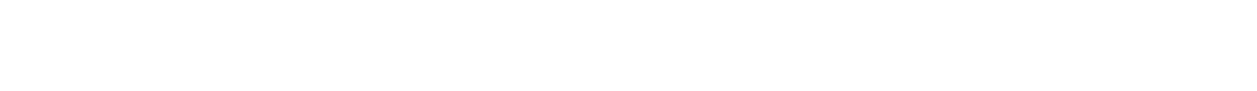

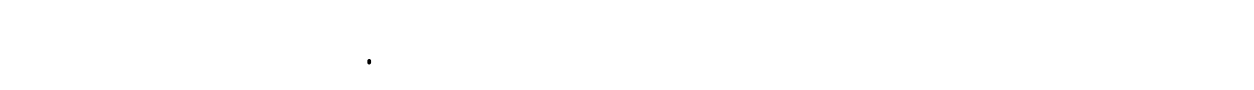

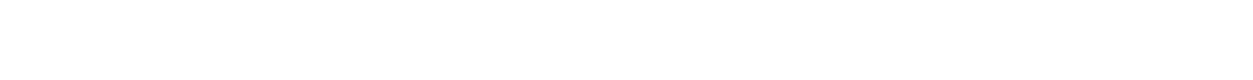

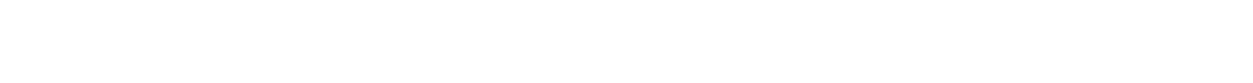

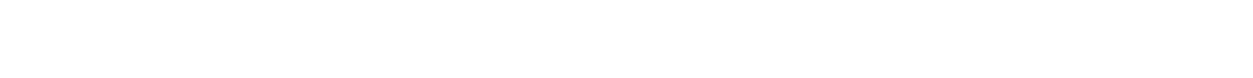

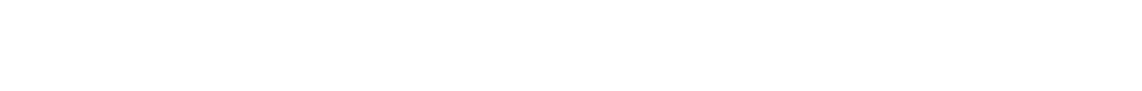

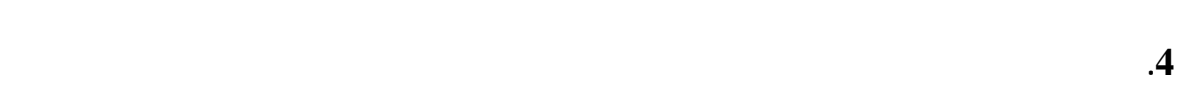

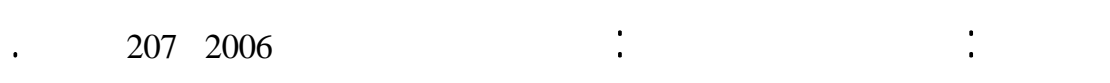

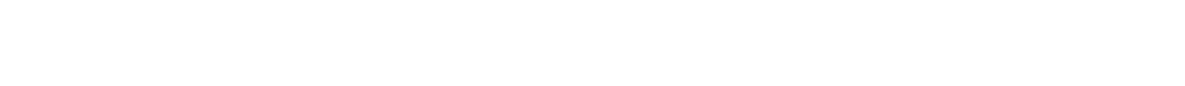

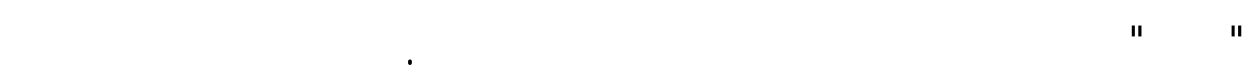

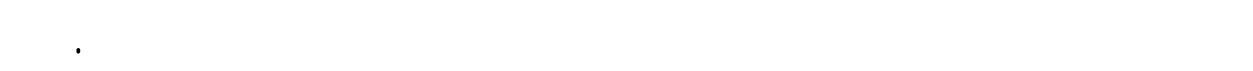




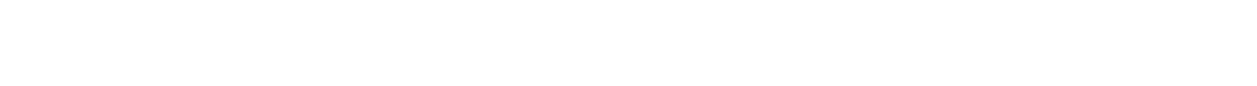

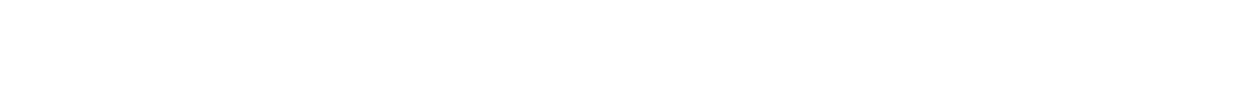

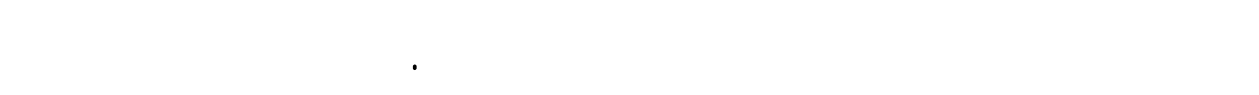

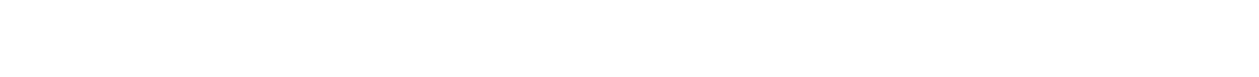

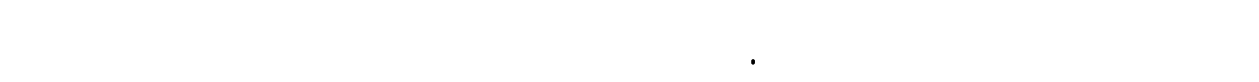

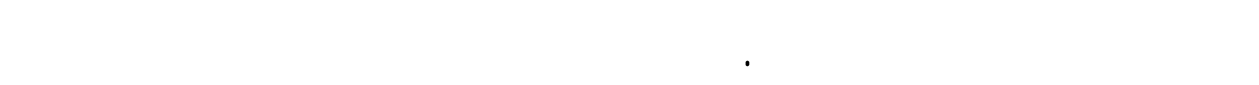

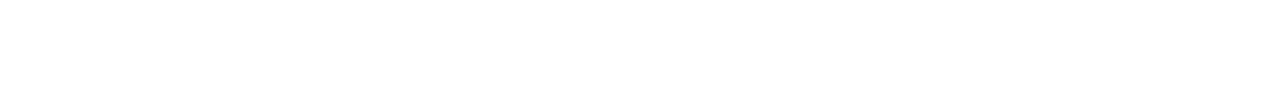

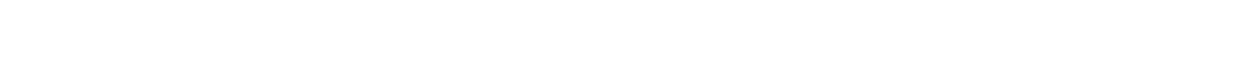

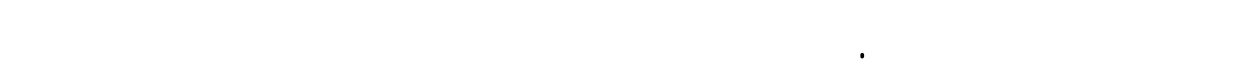

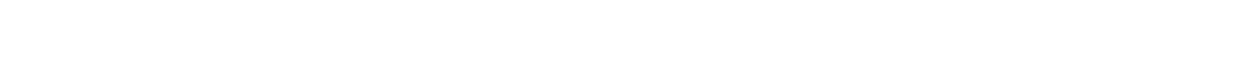

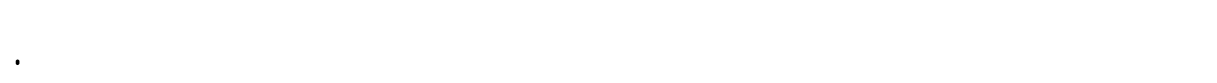

5. فهم السن الربلية، رضان لهيس زكي، القاهة، مكنة الشرق الدولة،

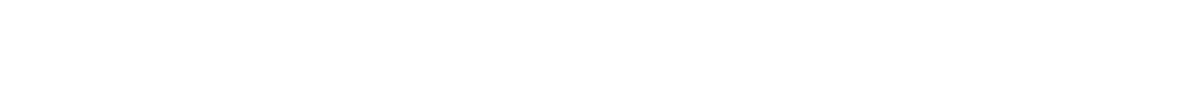

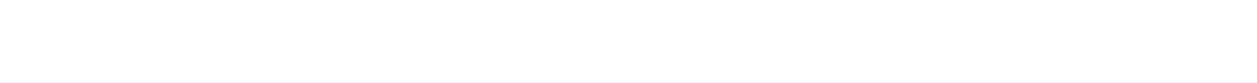

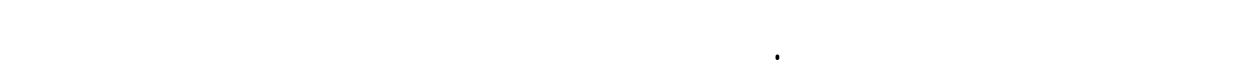

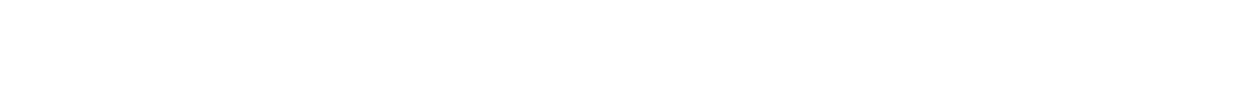

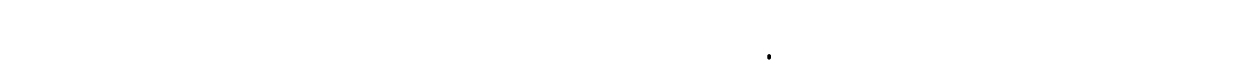

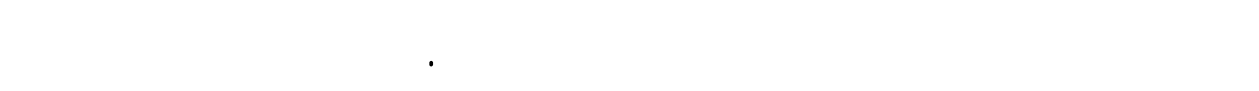

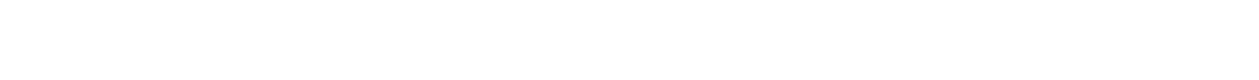

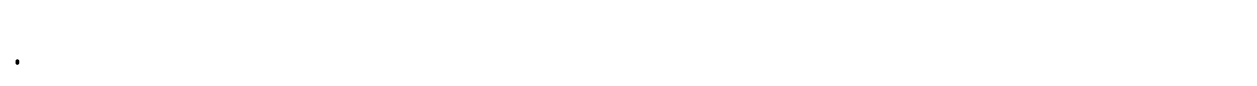

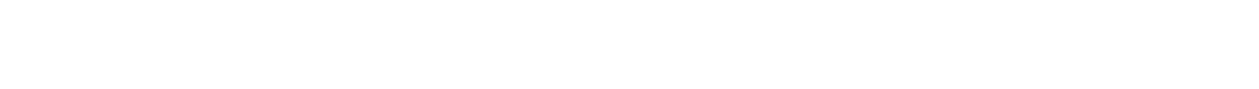

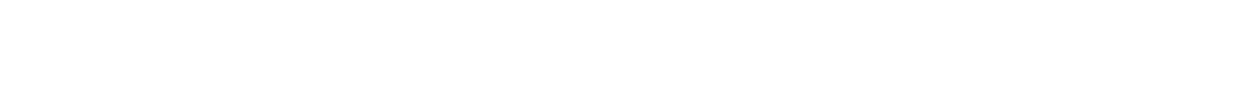

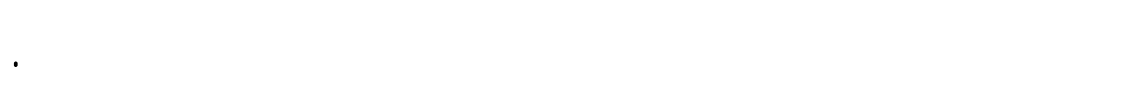




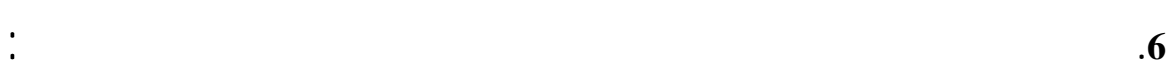

مركر درلست الوحة العربية، 2005،408صفهة.

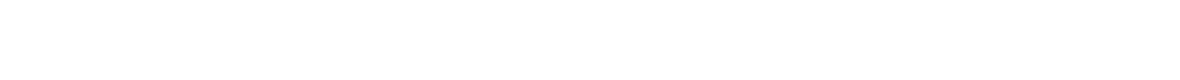

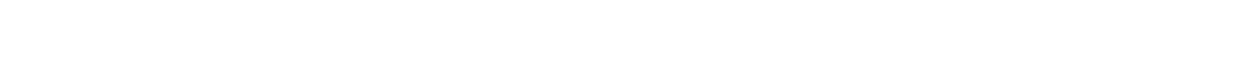

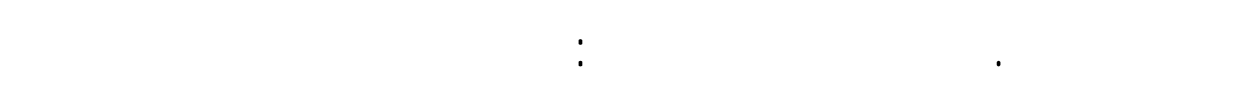

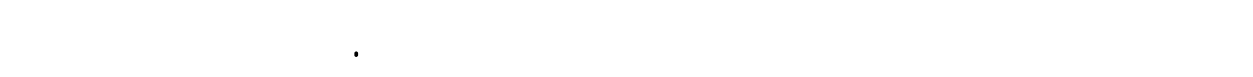

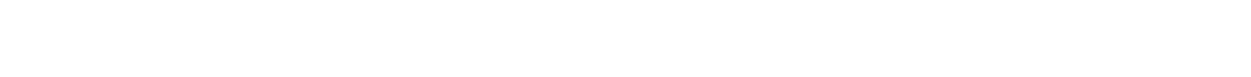

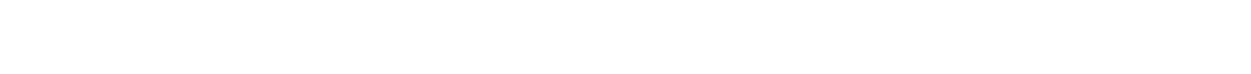

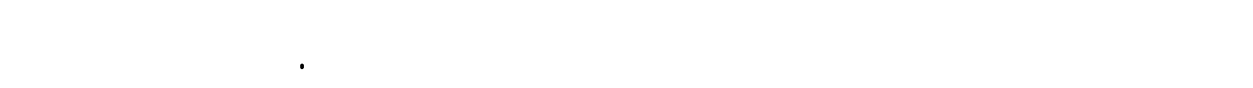

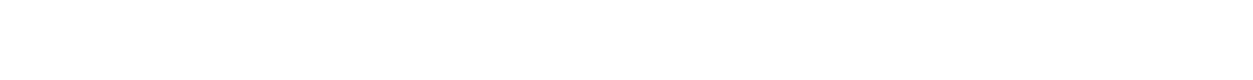

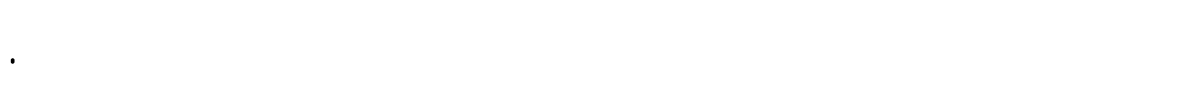

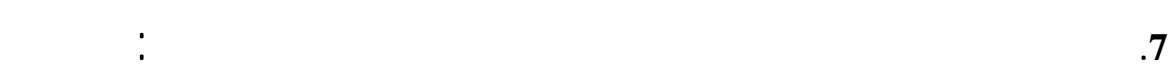

الثروق الدولية، 2006، 418صفحة.

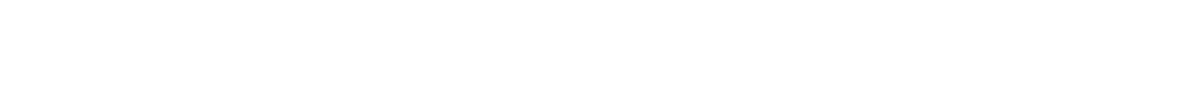

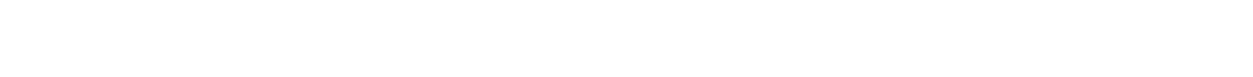

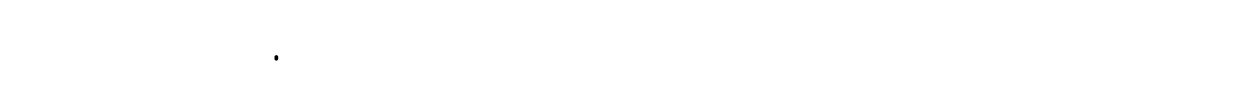

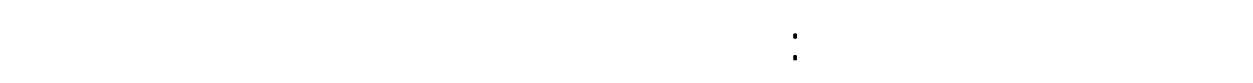

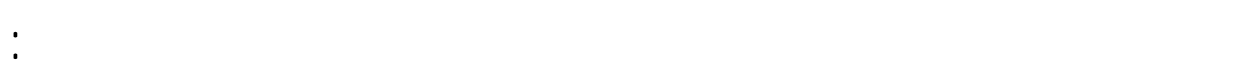

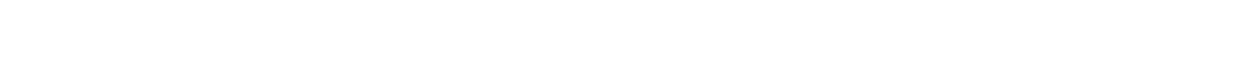

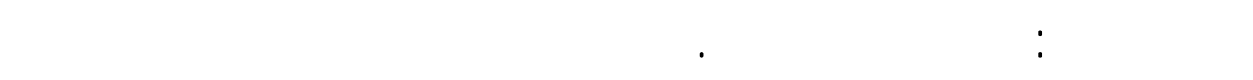

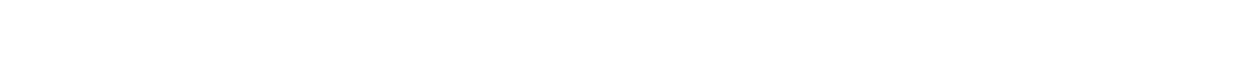

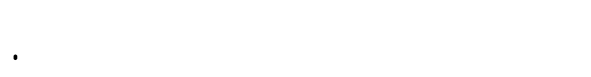




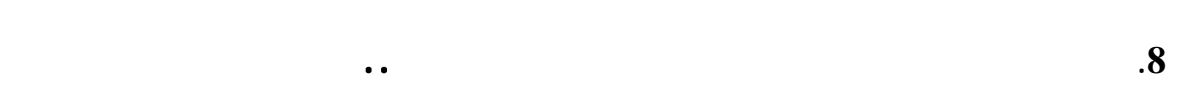

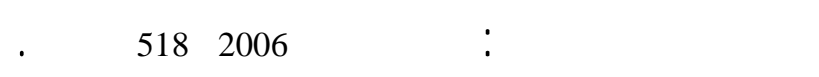

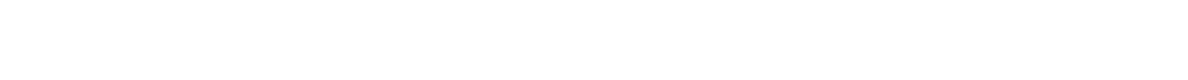

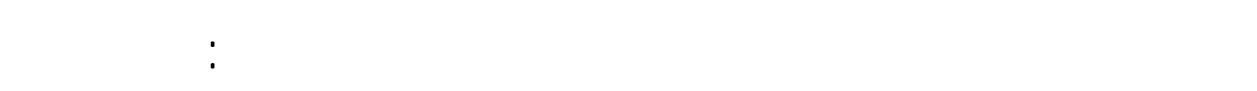

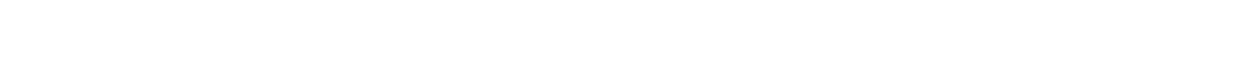

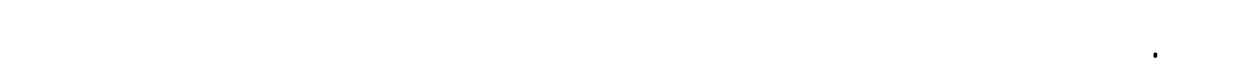

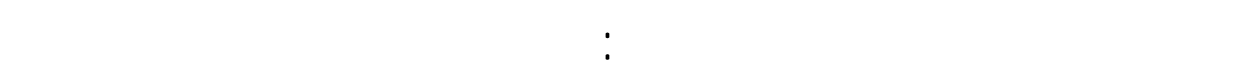

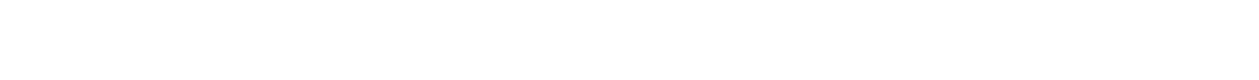

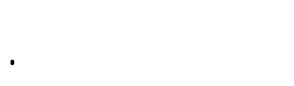

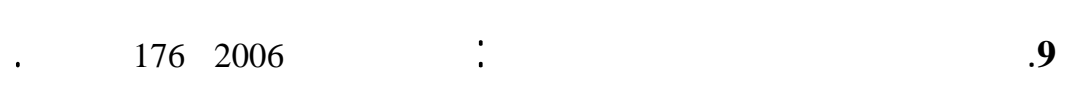

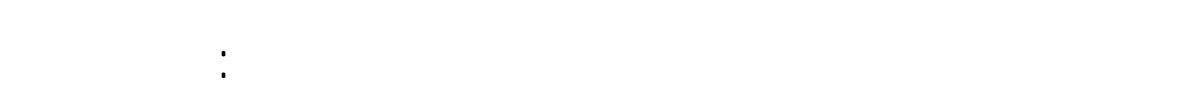

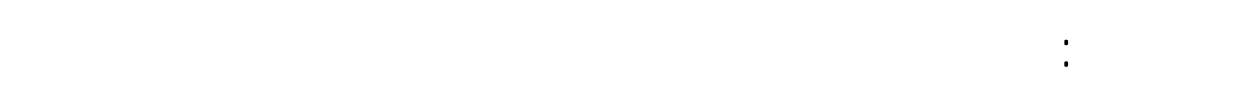

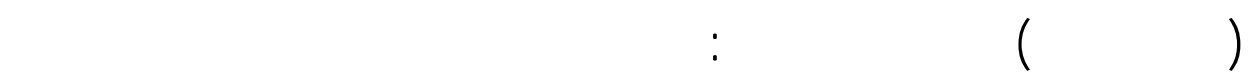

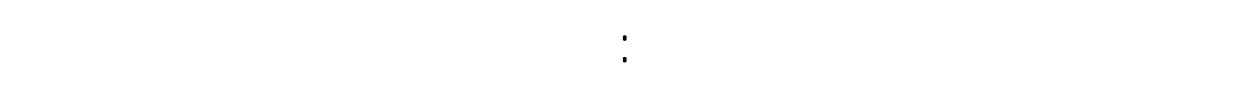

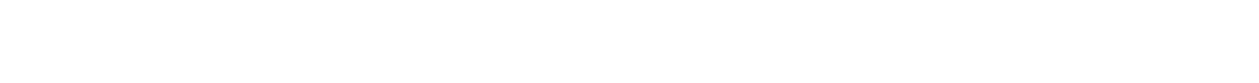

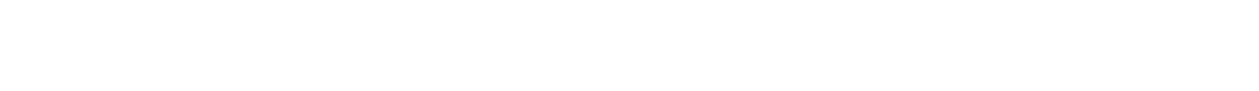

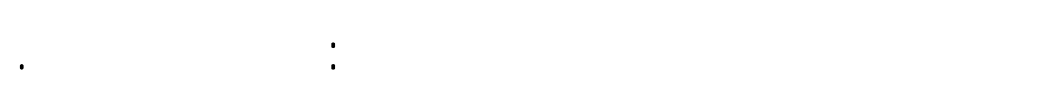

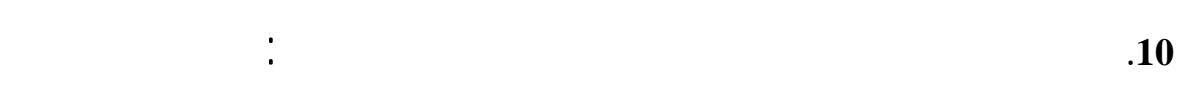
للعلوم، 2005، 159صفية.

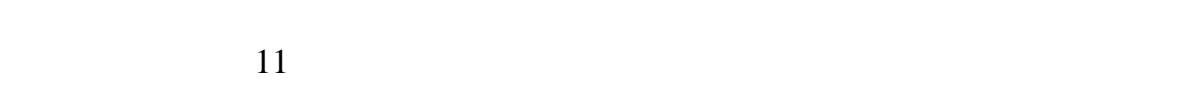

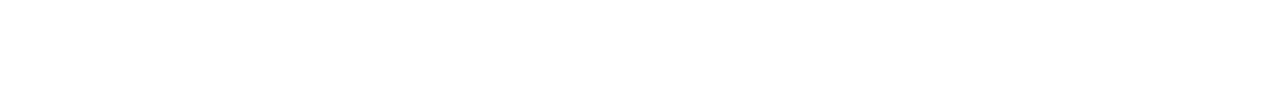

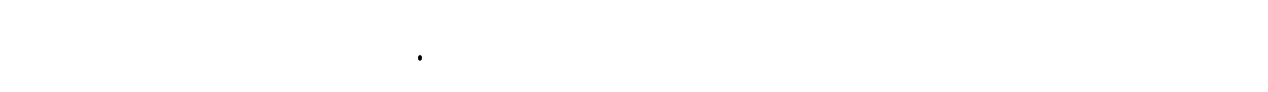

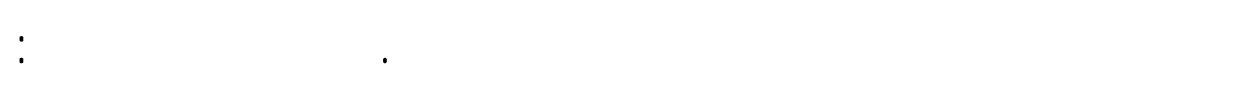


الفطل الأول بعنول: التجديد وآقل الإصلاح، وينلثن الـذور الديني ة والققلي ة

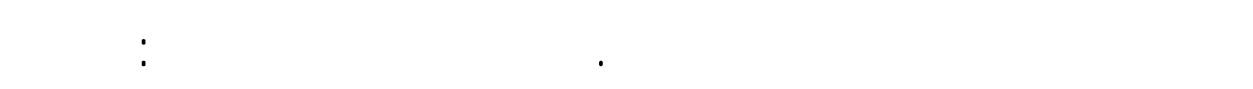

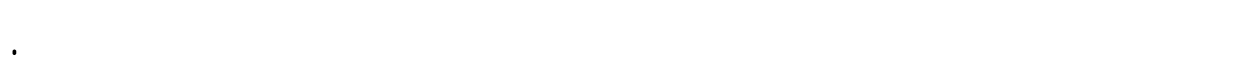

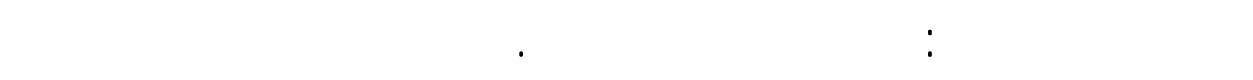

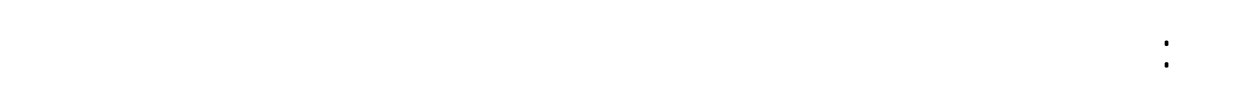

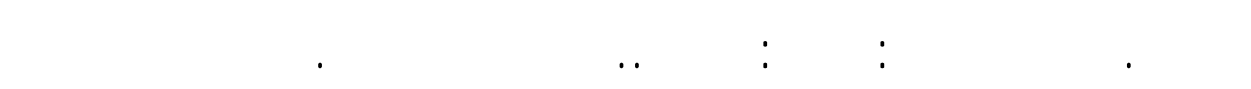

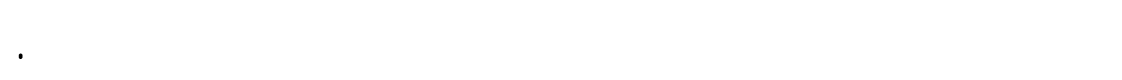

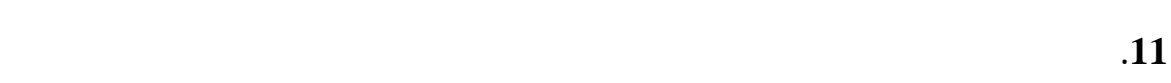

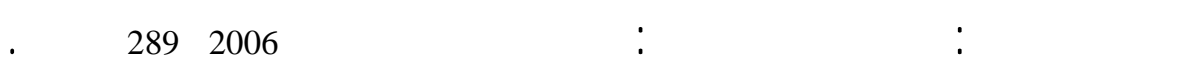

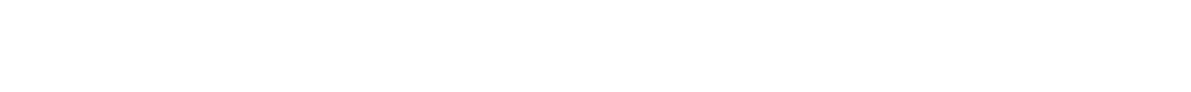

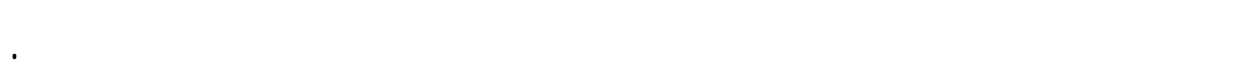

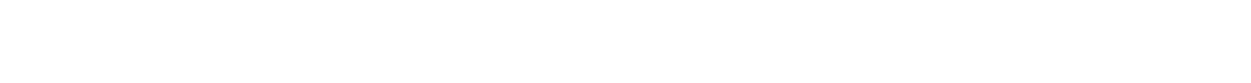

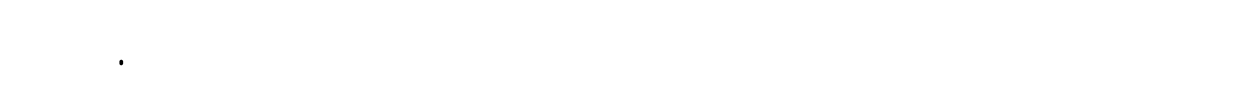

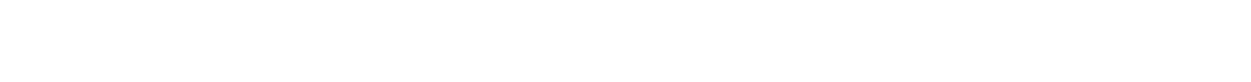

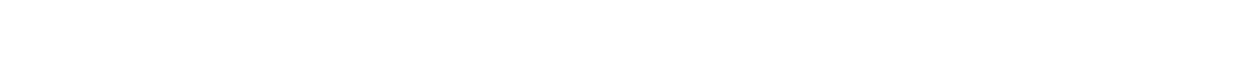

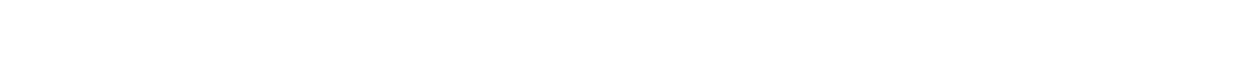

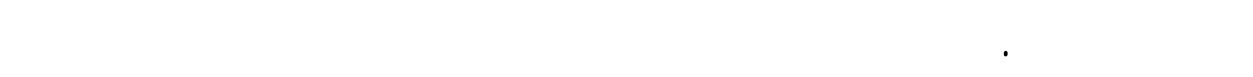

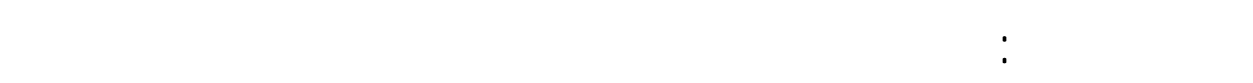

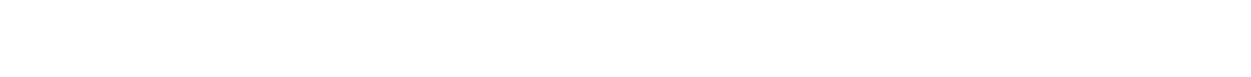

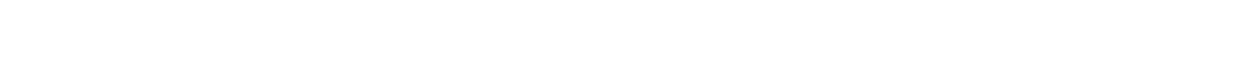

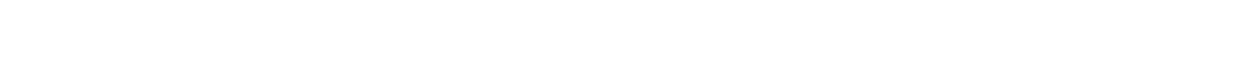
اللهسلمونشعوا وحكوملت إزاء ذلك؟

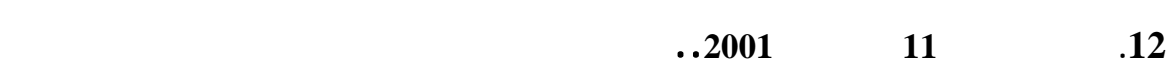

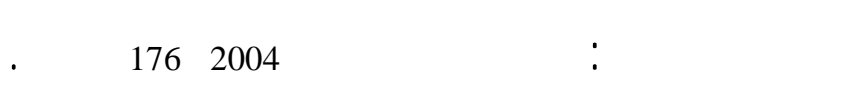




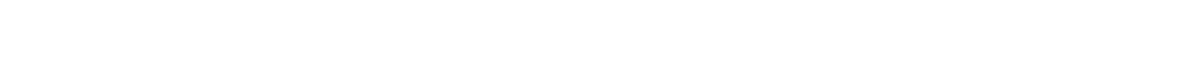

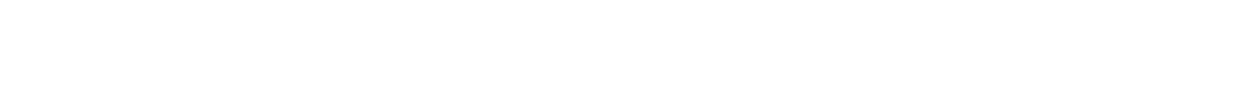

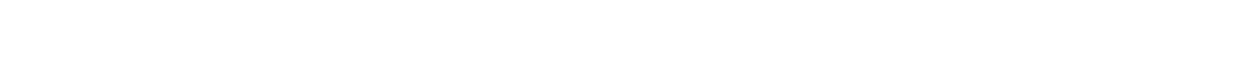

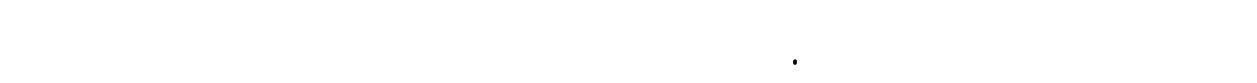

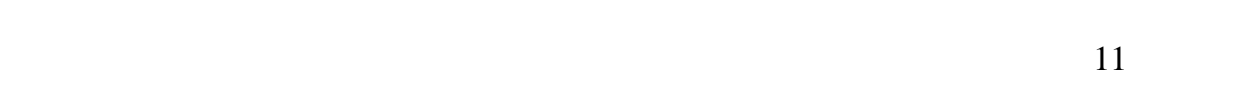

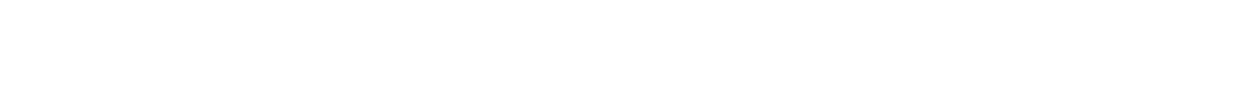

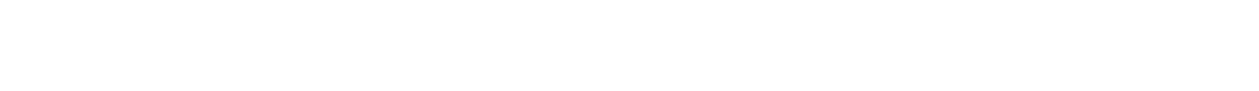

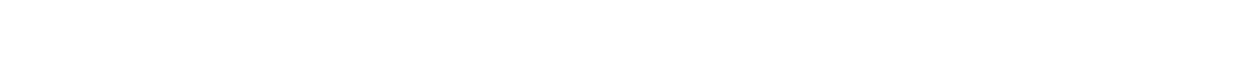

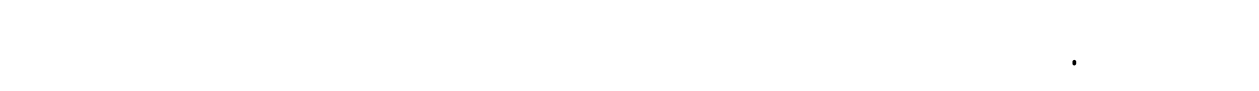

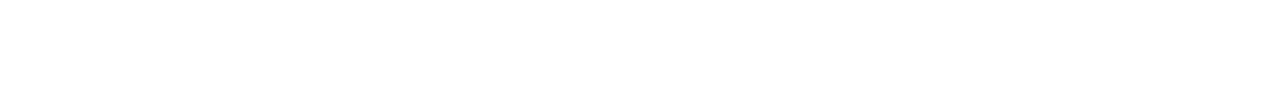

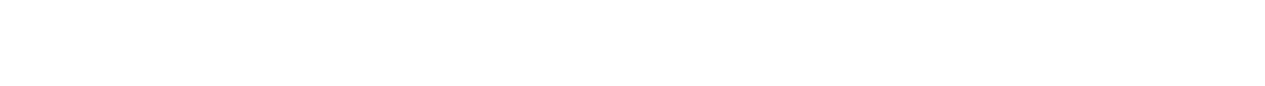

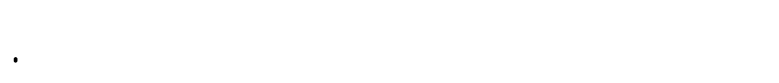

13. Global Political Islam: International Relations of the Muslim World, Pet Mandawille. Routledge; First Edition, 2007, p. 256

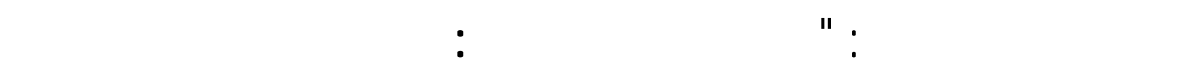

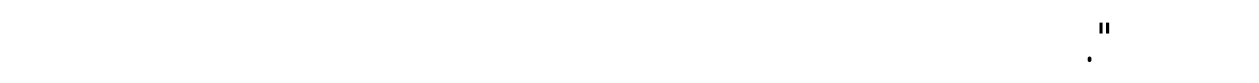

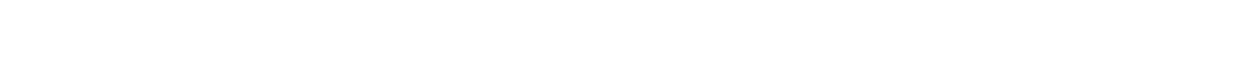

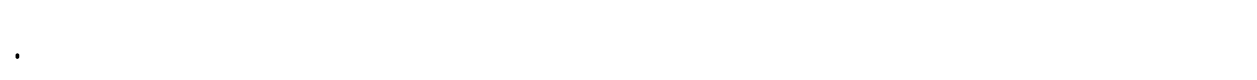

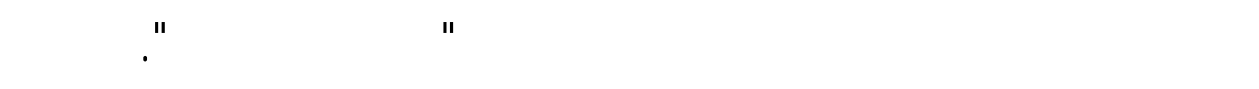

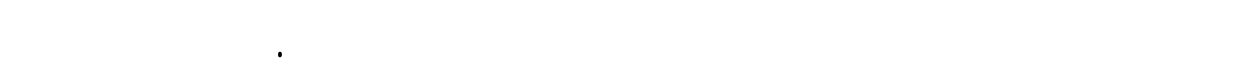

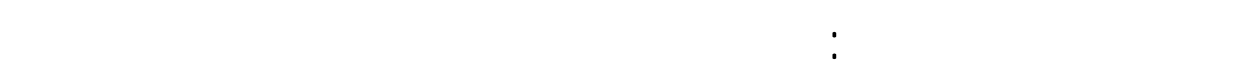

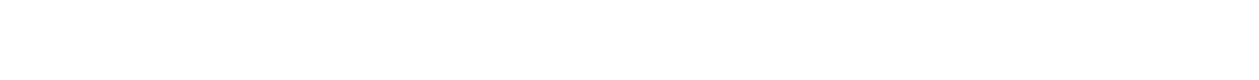

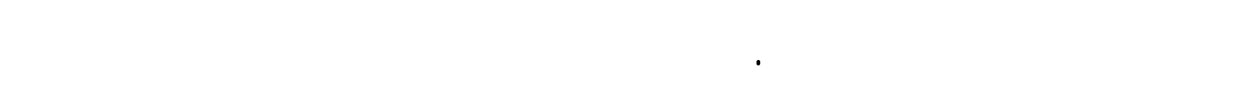

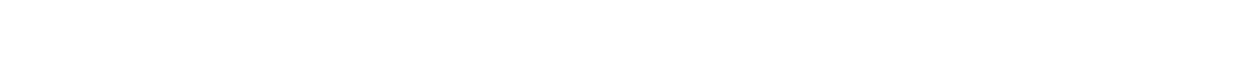




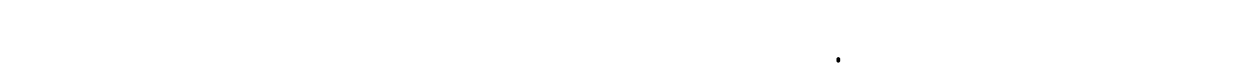

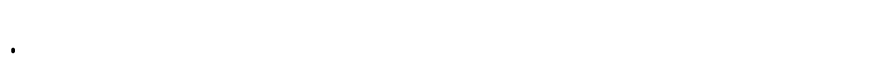

14. The Enemy of My Enemy: The Alarming Convergence of Militant Islam And the Extreme Right, George Michael, University Press of Kansas, 2006, p. 397

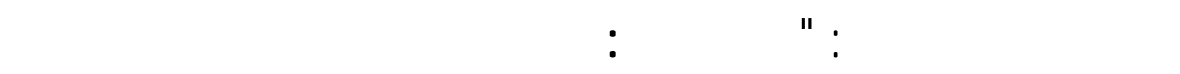

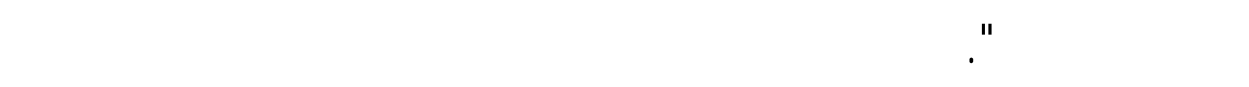

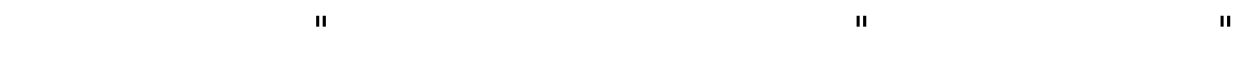

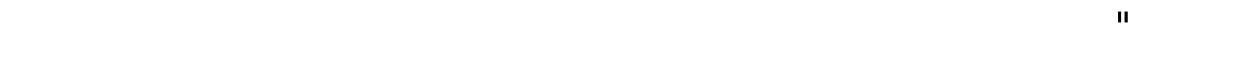

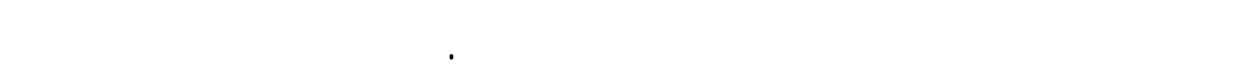

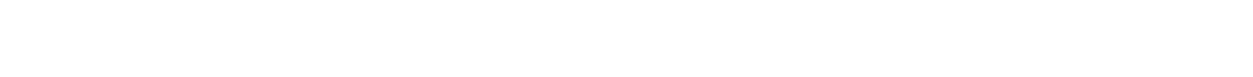

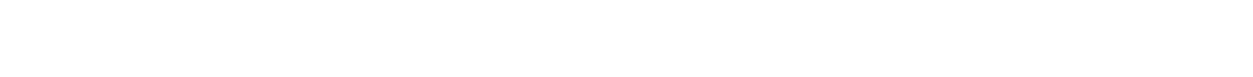

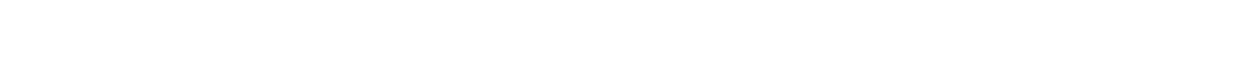

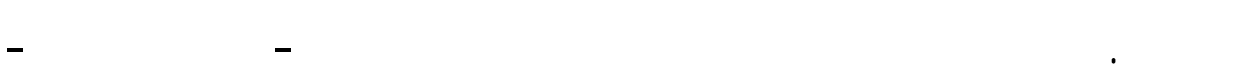

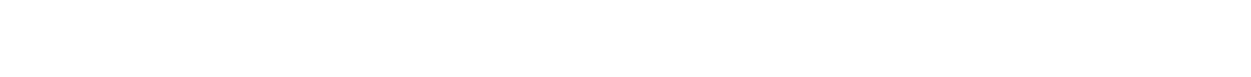

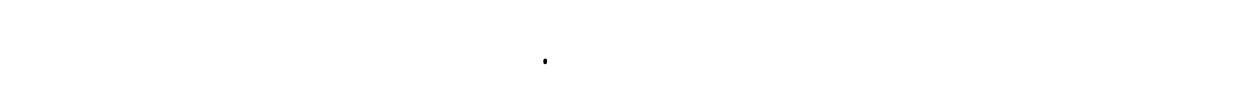

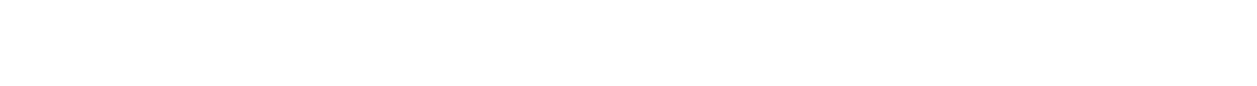

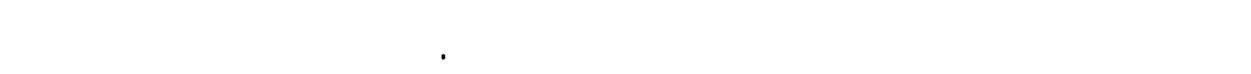

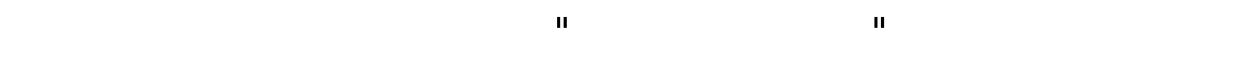

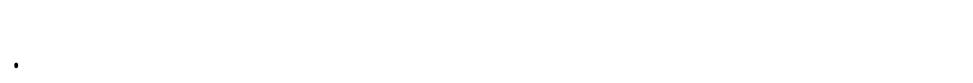

15. Tolerance and Coercion in Islam: Interfaith Relations in the Muslim Tradition (Cambridge Studies in Islamic Civilization), Yohanan Friedmann \& David Morgan, Cambridge University Press; 1st edition (May 31, 2006), p. 247

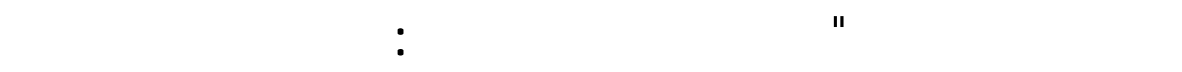

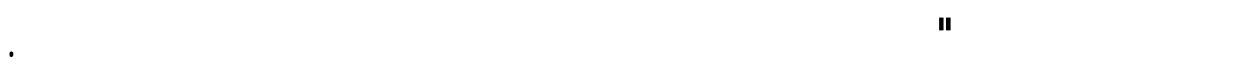




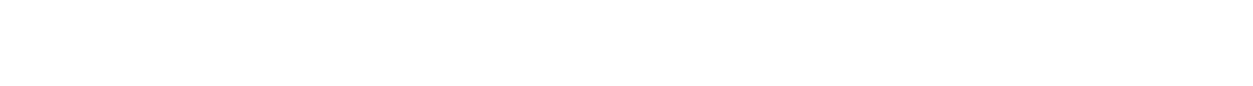

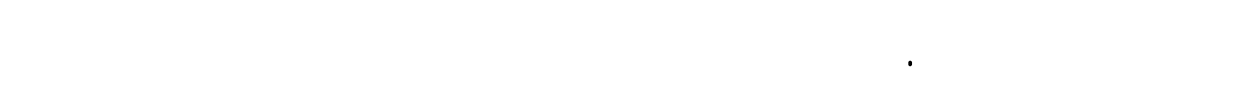

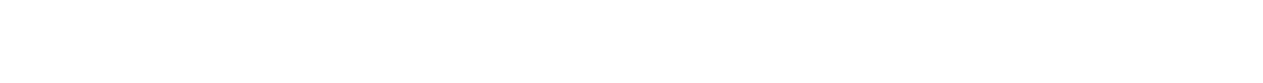

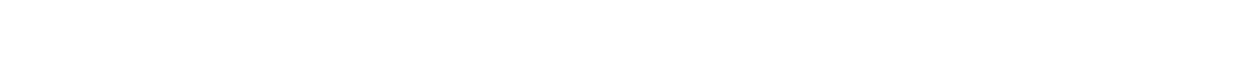

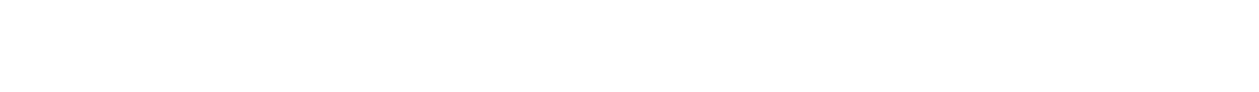

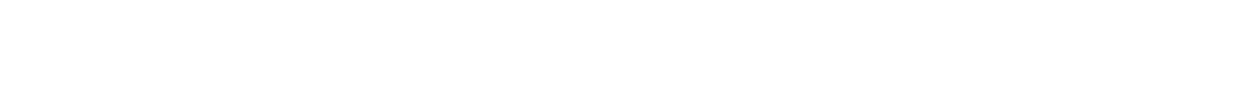

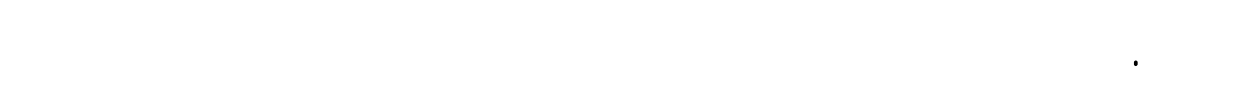

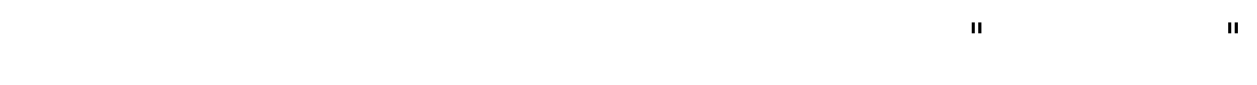

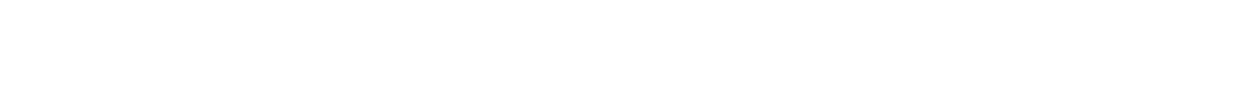

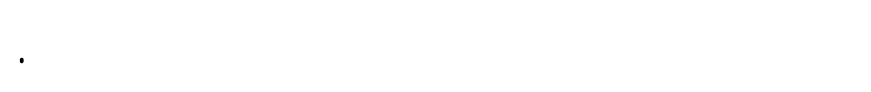

16. Islam without Fear: Egypt and the New Islamists, Raymond William Baker, Harvard University Press, 2003, p. 320

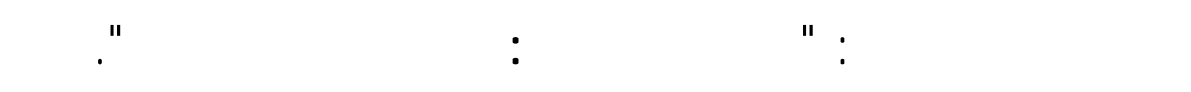

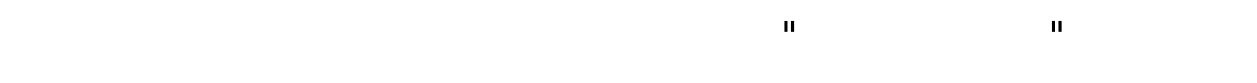

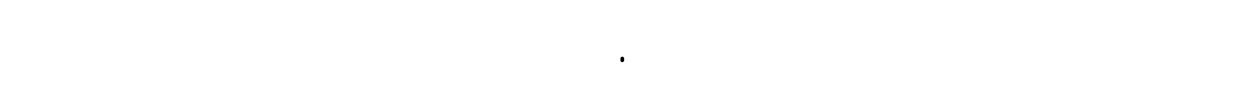

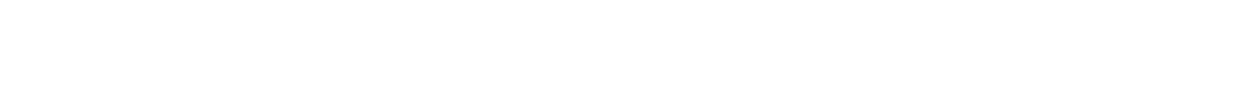

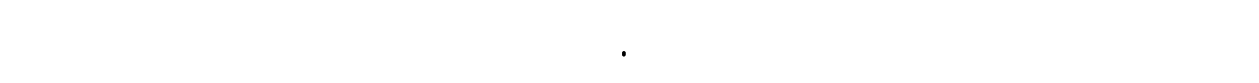

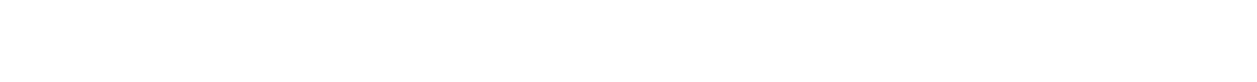

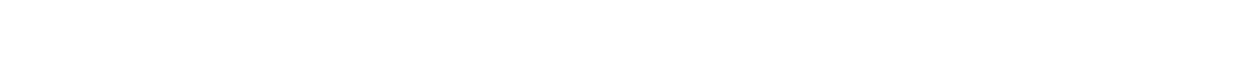

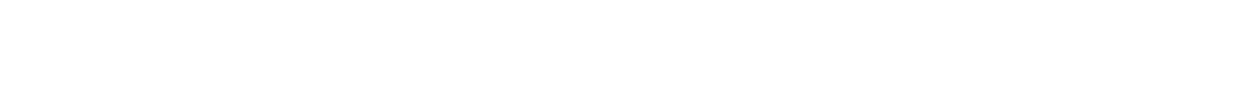

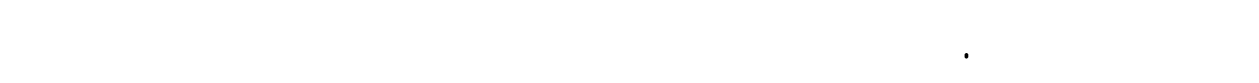

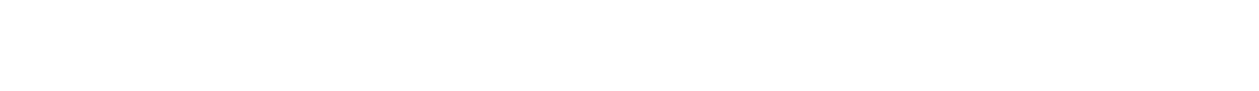

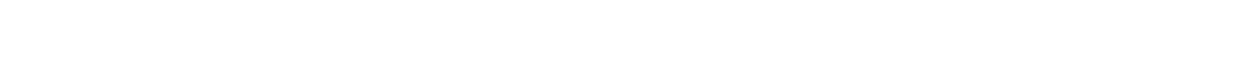

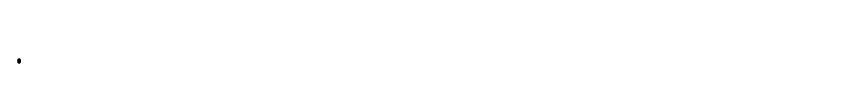


15. Off Center: The Republican Revolution and the Erosion of American Democracy, Jacob S. Hacker \& Paul Pierson, Yale University Press, 2005, P. 272

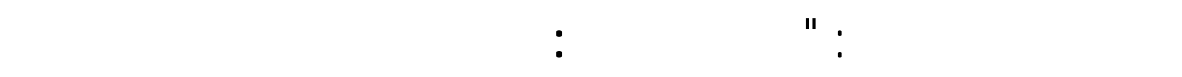

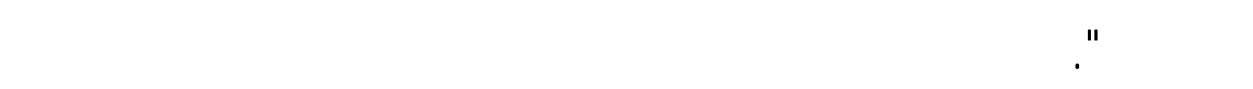

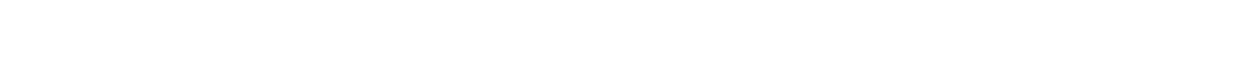

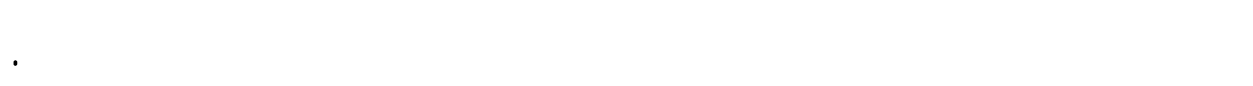

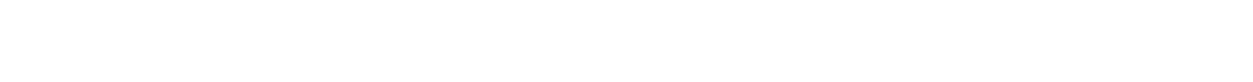

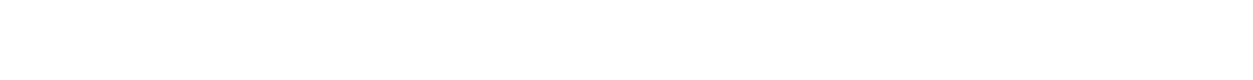

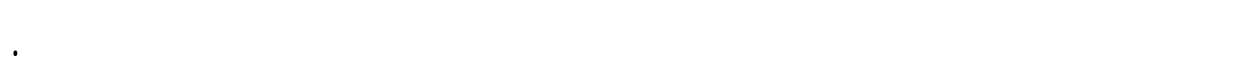

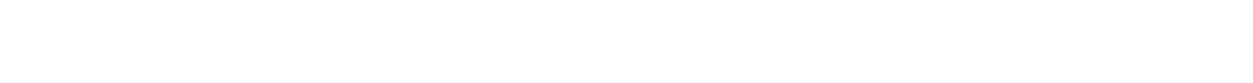

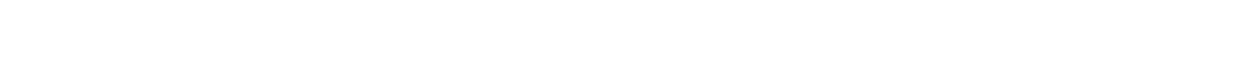

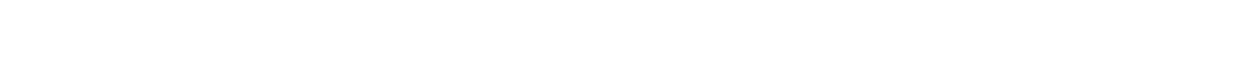

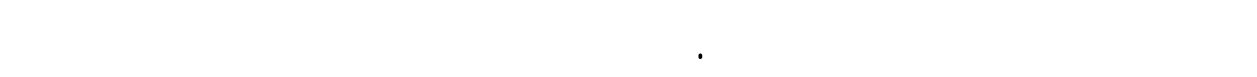

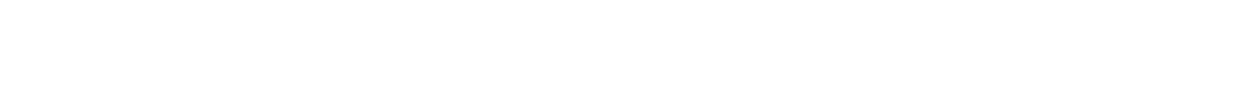

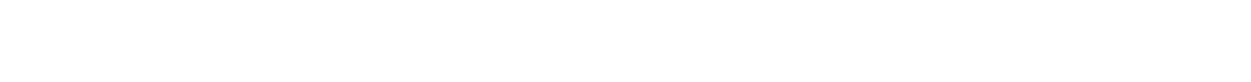

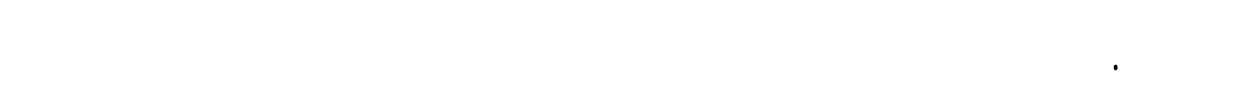

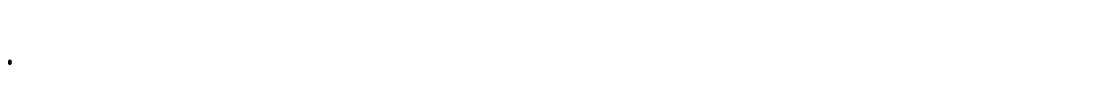

